\title{
Besnoitia besnoiti protein disulfide isomerase (BbPDI): Molecular characterization, expression and in silico modelling
}

\author{
Eduardo Marcelino a,b ${ }^{\mathrm{a}}$, Tiago M. Martins ${ }^{\mathrm{b}}$, Joana B. Morais ${ }^{\mathrm{a}, \mathrm{b}}$, Sofia Nolasco ${ }^{\mathrm{a}, \mathrm{c}}$, Helder Cortes ${ }^{\mathrm{d}}$, \\ Andrew Hemphill ${ }^{\mathrm{e}}$, Alexandre Leitão ${ }^{\mathrm{a}, *}$, Carlos Novo ${ }^{\mathrm{b}, *}$ \\ ${ }^{a}$ Instituto de Investigação Cientifica Tropical, CIISA, Faculdade de Medicina Veterinária, Universidade Técnica de Lisboa, Av. da Universidade Técnica, 1300-477 Lisboa, Portugal \\ ${ }^{\mathrm{b}}$ Unidade de Tecnologias de Proteínas e Anticorpos Monoclonais (UTPAM), Instituto de Higiene e Medicina Tropical, Campus do Lumiar, Estrada do Paço do Lumiar, 22, \\ Edificio F, r/c, 1649-38 Lisboa, Portugal \\ ${ }^{\mathrm{c}}$ Instituto Gulbenkian de Ciência, 2781-901 Oeiras, Portugal and Escola Superior de Tecnologia da Saúde de Lisboa, 1990-096 Lisboa, Portugal \\ ${ }^{\mathrm{d}}$ Laboratório de Parasitologia, Núcleo da Mitra, ICAM, Universidade de Évora, Apartado 94, 7000-554 Évora, Portugal \\ ${ }^{\mathrm{e}}$ Institute of Parasitology, Vetsuisse Faculty, University of Berne, Laenggass-Strasse 122, CH-3001 Bern, Switzerland
}

\section{A R T I C L E I N F O}

\section{Article history:}

Received 10 December 2010

Received in revised form 22 June 2011

Accepted 28 June 2011

Available online 3 July 2011

\section{Keywords}

Protein disulfide isomerase

Besnoitia besnoiti

Protein modelling

Recombinant protein

Phylogeny

\begin{abstract}
A B S T R A C T
Besnoitia besnoiti is an apicomplexan parasite responsible for bovine besnoitiosis, a disease with a high prevalence in tropical and subtropical regions and re-emerging in Europe. Despite the great economical losses associated with besnoitiosis, this disease has been underestimated and poorly studied, and neither an effective therapy nor an efficacious vaccine is available. Protein disulfide isomerase (PDI) is an essential enzyme for the acquisition of the correct three-dimensional structure of proteins. Current evidence suggests that in Neospora caninum and Toxoplasma gondii, which are closely related to B. besnoiti, PDI play an important role in host cell invasion, is a relevant target for the host immune response, and represents a promising drug target and/or vaccine candidate. In this work, we present the nucleotide sequence of the $B$. besnoiti PDI gene. BbPDI belongs to the thioredoxin-like superfamily (cluster 00388) and is included in the PDI_a family (cluster defined cd02961) and the PDI_a_PDI_a'_c subfamily (cd02995). A 3D theoretical model was built by comparative homology using Swiss-Model server, using as a template the crystallographic deduced model of Tapasin-ERp57 (PDB code 3F8U chain C). Analysis of the phylogenetic tree for PDI within the phylum apicomplexa reinforces the close relationship among B. besnoiti, N. caninum and $T$. gondii. When subjected to a PDI-assay based on the polymerisation of reduced insulin, recombinant BbPDI expressed in E. coli exhibited enzymatic activity, which was inhibited by bacitracin. Antiserum directed against recombinant BbPDI reacted with PDI in Western blots and by immunofluorescence with B. besnoiti tachyzoites and bradyzoites.
\end{abstract}

(c) 2011 Elsevier Inc. All rights reserved.

\section{Introduction}

Besnoitia besnoiti is a cyst-forming apicomplexan parasite of cattle with high veterinary relevance in many tropical and subtropical regions, with particular emphasis for sub-Saharan Africa (Bigalke and Prozesky, 2004). In Europe, besnoitiosis has been recently reported in Portugal (Cortes et al., 2005, 2006a), Spain (Castillo et al., 2009; Fernandez-Garcia et al., 2010; Irigoien et al., 2000), France (Alzieu et al., 2007; Bourdeau et al., 2004; Lienard et al., 2010), Italy (Agosti et al., 1994; Gollnick et al., 2010) and Germany (Mehlhorn et al., 2009; Schares et al., 2009). There is no treatment against this infection despite the efforts to identify and develop effective agents (Cortes et al., 2007; Shkap et al., 1987). Live-attenuated vaccines have been used in Israel

\footnotetext{
* Corresponding authors. Fax: +351213652 869 (A. Leitão), +35121716 3636 (C. Novo).

E-mail addresses: alexandre@fmv.utl.pt (A. Leitão), cnovo@ihmt.unl.pt (C. Novo).
}

and South Africa (Basson et al., 1970) but they do not prevent subclinical infection and their use is geographically limited. Therefore, there is an urgent need for studying potential drug targets and vaccine candidates. Protein disulfide isomerase (PDI) is a key enzyme that enables proteins to acquire their correct threedimensional structure (Appenzeller-Herzog and Ellgaard, 2008; Hatahet et al., 2009; Wilkinson and Gilbert, 2004). This enzyme, one of the most abundant in the endoplasmic reticulum (ER) and classically described as an ER-resident protein (Lambert and Freedman, 1985), is a member of the thioredoxin superfamily (Ferrari and Soling, 1999) and consists of two homologous catalytic domains, $\mathbf{a}$ and $\mathbf{a}^{\prime}$, comprising each an active site with a CxxC motif, separated by two homologous non-catalytic domains, $\mathbf{b}$ and $\mathbf{b}^{\prime}$, and a highly acidic C-terminal extension c (Byrne et al., 2009; Edman et al., 1985; Kemmink et al., 1999; Kozlov et al., 2010). PDI catalyses disulfide formation and the rearrangement of incorrect disulfide pairing during the oxidative protein folding process (Schwaller et al., 2003; Wilkinson and Gilbert, 2004). Misfolded 
proteins can lose their functionality and accumulate as large, insoluble aggregates that might interfere with cell viability (Wilkinson and Gilbert, 2004). Current evidence suggests that PDIs are also involved in a wide range of other biological functions in many cellular compartments including the cell surface, where they may participate in the reducing exterior environment and/or may be involved in cell adhesion (Turano et al., 2002). Parasite PDI-like enzymes were identified in Neospora caninum (Naguleswaran et al., 2005), Toxoplasma gondii (Meek et al., 2002a,b), Theileria parva (Ebel et al., 2002), different Leishmania species (Hong and Soong, 2008; Ben et al., 2002; Padilla et al., 2003), Cryptosporidium parvum (Blunt et al., 1996) and several species of Plasmodium (Florent et al., 2000; Mahajan et al., 2006; Mouray et al., 2007; Novo et al., 2009). $T$. gondii and $N$. caninum, both closely related to B. besnoiti (Ellis et al., 2000), have been shown to express highly homologous molecules, which could indicate that PDI plays a key role in the biology of neosporosis and toxoplasmosis (Ma et al., 2009; Meek et al., 2002a; Naguleswaran et al., 2005). In this way, the important role of PDI in these two species and presumably in other apicomplexan parasites as well, might not allow for the accumulation of a large number of mutations in the protein sequence, rendering this molecule an interesting drug target. In fact, bacitracin and anti-PDI antibodies are effective at inhibiting the enzymatic activity of PDI in CHO cells (Mandel et al., 1993), and allowed the demonstration of the fundamental role of PDI in N. caninum host cell invasion (Naguleswaran et al., 2005). Furthermore, T. gondii PDI is targeted by mucosal IgA in humans (Meek et al., 2002a) and $N$. caninum PDI by IgA in cattle (Liao et al., 2006), suggesting that PDI specific antibodies may be involved in the host defence against these parasites. In addition, the analysis of $N$. caninum antigenic proteins identified PDI as one of the immunodominant proteins associated with the processes of invasion, proliferation and egress of apicomplexan parasites (Shin et al., 2004, 2005). The inhibitory effect of $N$. caninum PDI antiserum on the growth of this parasite was also demonstrated (Liao et al., 2006). Recently, intranasal vaccination of mice with recombinant $N$. caninum PDI conferred $90 \%$ protection against disease and significantly reduced the cerebral parasite burden and the numbers of viable (live) tachyzoites in brain tissue (Debache et al., 2010). All the evidence obtained so far points towards the importance of PDI in the host immune response and cell invasion process, and prompted us to characterize this molecule in $B$. besnoiti.

\section{Materials and methods}

\subsection{Tissue culture and parasite purification}

The $B$. besnoiti Bb1Evora03 strain was maintained by serial passages in confluent monolayers of Vero cells grown in DMEM supplemented with $10 \%$ heat-inactivated fetal bovine serum, $20 \mathrm{mM}$ HEPES pH 7.2-7.5, amphotericin B $(250 \mu \mathrm{g} / \mathrm{ml}), 2 \mathrm{mM}$ s-glutamine, penicillin $(100 \mathrm{U} / \mathrm{ml})$, and streptomycin $(100 \mu \mathrm{g} / \mathrm{ml})$, as previously described (Cortes et al., 2006b; Reis et al., 2006). For parasite purification, freshly egressed tachyzoites were collected from the cell cultures supernatants, passed three times through a $25 \mathrm{G}$ needle, were washed three times with PBS, and passed through PD10 columns according to the manufacturer's instructions (GE Healthcare). Bradyzoites were obtained from cysts in skin biopsies by mechanical disruption with an $18 \mathrm{G}$ syringe needle and liberated parasites were washed and purified as above.

\subsection{B. besnoiti PDI-gene sequence}

B. besnoiti tachyzoites were purified from in vitro cultures, and genomic DNA was isolated using DNeasy Blood and Tissue Kit
(Qiagen). Primers for the initial PCR amplifications were designed based on conserved regions of the aligned PDI nucleotide sequences from $N$. caninum (AY751081) and T. gondii (AJ312317). PCR amplification was carried out in a $20 \mu \mathrm{l} \mathrm{PCR} \mathrm{mixture}(1 \times$ reaction buffer, $1 \mathrm{U}$ of Taq DNA polymerase (Fermentas), 10 pmol of each primer, and $0.2 \mathrm{mM}$ dNTP's), using $B$. besnoiti genomic DNA, primers PDIBesF2 (5'-GAGTGGATCGAGAAGATG-3') and PDIBesR2 (5'-GTGCCGTCCATCTTGGCAACA- $\left.3^{\prime}\right)$, and running 30 cycles $\left(90^{\circ} \mathrm{C}\right.$ for $30 \mathrm{~s}, 55^{\circ} \mathrm{C}$ for $1 \mathrm{~min}, 72^{\circ} \mathrm{C}$ for $1 \mathrm{~min} 15 \mathrm{~s}$ ). PCR products were cloned in the pTZ57R/T vector (Fermentas), and sequenced in both directions by dideoxy-chain termination method (Sanger et al., 1977). Primers for genome walking were designed based on the sequence obtained.

Genome walking libraries were generated and amplifications were carried out according to the manufacturer's instructions (Clontech, USA). $2.5 \mu \mathrm{g}$ of genomic DNA was digested separately with AluI, HaeIII, HpaI or SmaI. Subsequently, the GenomeWalker adaptors were ligated to the DNA. PCR amplification of DNA fragments from genomic libraries was carried out using Taq DNA polymerase (Fermentas) and gene-specific primers PDIBesGWF1 (5'-AGGAGGCTGTCAAGGTTGTCGTCGGCAAGA-3') PDIBesGWF2 (5'-GATCTACGCTCCGTGGTGCGGCTACTGCAA-3') PDIBesG WR1 (5'-AAGTTCTCGGCGTTGATGGGGCCAAGCAGA-3') and PDIBesGWR2 (5'-GCCACTGAAGTCGTCAGTGCCCTCCTCGTA-3'). After the first genome walking, the products were cloned and sequenced and a second round of amplification was done with primers PDIBesGWR3 (5'-CGAGACATGCTGCTTTTGGAGGCCGACCAA-3') and PDI BesGWR4 (5'-GAAGCGACGCTGTCTGGAGACGTTCTGCAA-3'). All clones were again sequenced in both directions, as above.

\subsection{Production of recombinant B. besnoiti PDI (recBbPDI)}

\subsubsection{Cloning and sequencing of $B$. besnoiti PDI $c D N A$}

For cDNA synthesis, $B$. besnoiti tachyzoites were purified from in vitro cultures and total RNA was extracted (High Pure RNA Isolation Kit - Roche). RNA obtained from $10^{8}$ tachyzoites was reverse transcribed by a two-step RT-PCR procedure (First Strand cDNA Synthesis Kit - Fermentas) for the production of cDNA. The PDI ORF was PCR-amplified using the forward primer PDIBesEX1 (5'gaatccATGCGGGCTGGGGTCTGCTACCT-3') and the reverse primer PDIBesEX2 (5'-gctcgagTTACAATTCCTCGCCCTTGTCGTCCT-3'), that contain EcoRI and XhoI sites respectively, and cDNA as template. Amplification was carried out using the conditions described above and performing 30 cycles $\left(90^{\circ} \mathrm{C}\right.$ for $30 \mathrm{~s}, 60^{\circ} \mathrm{C}$ for $1 \mathrm{~min}, 72^{\circ} \mathrm{C}$ for $1 \mathrm{~min} 15 \mathrm{~s}$ ). PCR products were cloned into the pTZ57R/T vector (Fermentas), and sequenced.

\subsubsection{Plasmid construction and expression}

Full-length $B$. besnoiti PDI cDNA was released from pTZ57R-PDI by restriction-reactions with EcoRI and XhoI, subcloned into pGEX$6 \mathrm{P}-1$ expression vector hydrolysed with the same enzymes, and sequenced for confirmation. Production and purification of recombinant glutathione S-transferase (GST) fusion protein was conducted according to the manufacturer's recommendation (GE Healthcare). Briefly, the pGEX-6P-PDI construct was transformed into E. coli BL21 cells, cultures were grown in liquid broth and induced when $\mathrm{ABS}_{600 \mathrm{~nm}} \approx 0.8$ for $2 \mathrm{~h}$ with $1 \mathrm{mM}$ IPTG. The cell pellet was collected and lysis was performed by sonication. The recombinant $B$. besnoiti PDI (recBbPDI) was purified from the lysate using Glutathione Sepharose 4B and following the brand indications with the exception that $0.1 \%$ Triton X-100 was used in binding and washing steps. Protein quantification was performed using a NanoDrop 2000 spectrophotometer assuming an extinction coefficient of $93000 \mathrm{M}^{-1} \mathrm{~cm}^{-1}$ and a molecular weight of $81 \mathrm{kDa}$. 


\subsection{Determination of the reductase activity of recBbPDI and its inhibition by bacitracin}

RecBbPDI activity was measured by a turbidimetric assay based on the polymerization of reduced insulin (Lundstrom and Holmgren, 1990) as adapted by Smith et al. (2004). Commercial bovine PDI (Sigma) was used as a control. Briefly, the assay was performed in 96-well microtiter plates and all solutions were made with assay buffer: $100 \mathrm{mM}$ potassium phosphate, $2 \mathrm{mM}$ EDTA, $\mathrm{pH}$ 7. Bacitracin, at concentrations ranging from $0.5 \mathrm{mM}$ to $4 \mathrm{mM}$, or assay buffer $(5 \mu \mathrm{L})$ were added to respective wells; the reaction solution was made by mixing $70 \mu \mathrm{L}$ assay buffer with $10 \mu \mathrm{L}$ of insulin $(1.6 \mathrm{mM}$ ) and the enzymes or buffer (blank); $75 \mu \mathrm{L}$ of reaction solution were added to each well and the reaction was started with $20 \mu \mathrm{L}$ of $5 \mathrm{mM}$ DTT. Absorbance at $650 \mathrm{~nm}$ was read in a SECTRAmax ${ }^{\circledR} 340 \mathrm{pc}$ microplate spectrophotometer over 60 min every 5 min. Enzyme activity was calculated from the increase of turbidity over time $\left(\left(\mathrm{ABS}_{650}\right.\right.$ at each time point - $\mathrm{ABS}_{650}$ at time zero $)_{\text {enzyme }}-\left(\mathrm{ABS}_{650}\right.$ at each time point $-\mathrm{ABS}_{650}$ at time zero) blank).

\subsection{Antiserum production}

One mouse was immunized intraperitoneally three times in intervals of three weeks, with approximately $10 \mu \mathrm{g}$ of recBbPDI emulsified in Freund's incomplete adjuvant (MP Biomedicals, Inc.). The animal had free access to food and water and was housed and managed according to the applicable National and EU regulations. Four days after the last injection the mouse was bled and the specific anti-recBbPDI antibody titre determined by enzyme-linked immunosorbent assay (ELISA). Briefly, coating was performed with $0.1 \mu \mathrm{g} /$ well of recBbPDI and alkaline phosphatase-conjugated secondary antibodies were used with $p$-nitrophenylphosphate (Sigma) $\left(1 \mathrm{mg} \mathrm{mL}^{-1}\right)$ in $100 \mathrm{mM}$ glycine containing $1 \mathrm{mM} \mathrm{MgCl}_{2}$ and $1 \mathrm{mM} \mathrm{ZnCl}_{2}$, pH 10.4 as enzyme substrate. The plate was incubated $30 \mathrm{~min}$ in the dark at room temperature and the reaction stopped by the addition of $50 \mu \mathrm{L} 3 \mathrm{~N} \mathrm{NaOH}$. Absorbance was read at $405 \mathrm{~nm}$ in a TIM 200 Inter Med plate reader.

\subsection{Western blotting}

Protein samples were prepared from purified tachyzoites or bradyzoites. The cellular pellet $\left(10^{8}\right.$ parasites) was resuspended in Laemmli sample buffer (BioRad) and heated for $5 \mathrm{~min}$ at $95^{\circ} \mathrm{C}$. Proteins were separated by SDS-PAGE (12.5\%) under reducing conditions and blotted onto nitrocellulose (Millipore) at $100 \mathrm{~V}$ for $1 \mathrm{~h}$ in Tris-glycine buffer with $20 \%(\mathrm{v} / \mathrm{v})$ methanol. The membranes were blocked overnight at $4{ }^{\circ} \mathrm{C}$ with $1 \%$ fish gelatin (Sigma) and probed with mouse anti-recBbPDI followed by incubation with alkaline phosphatase-conjugated goat anti-mouse-IgG secondary antibody (Sigma) diluted 1:5000. The final enzyme reaction was developed using the BCIP/NBT kit (Bio-Rad).

\subsection{Immunofluorescence}

Purified tachyzoites or bradyzoites were allowed to adhere to poly-L-lysine-coated microscopy coverslips for $30 \mathrm{~min}$, and were fixed for $10 \mathrm{~min}$ with cold $\left(-20^{\circ} \mathrm{C}\right)$ methanol. Parasites were then probed with mouse anti-recBbPDI serum and FITC-conjugated anti-mouse antibodies (Invitrogen). To visualize the entire cells, parasites were simultaneously probed with rabbit anti-B. besnoiti (Cortes et al., 2006b) and TRITC-conjugated anti-rabbit antibodies (Invitrogen). All these sera were used at 1:500 dilutions. DNA was stained with DAPI ( $1 \mu \mathrm{g} \mathrm{mL}^{-1}$; Sigma) for $2 \mathrm{~min}$ and the slides were mounted with Mowiol (Calbiochem) and examined under a UV light microscope.

\subsection{Database search and biocomputing approaches}

Similarity searches on the Protein databank were done using the Blast search program (Altschul et al., 1990). Alignment between two protein amino acid sequences was done using SIM (<http://expasy.org/tools/sim-prot.html>) (Huang and Miller, 1991). Multiple sequence alignment of PDI amino acid sequences was performed using MEGA 4 and ClustalW (Kumar et al., 2008). Search for BbPDI neighbors and phylogenic tree construction were performed using the web server phylogeny.fr (<http://www.phylogeny.fr $>$ ) (Dereeper et al., 2008). Pattern search was performed using ScanProsite (<http://expasy.org/prosite/>) (Gattiker et al., 2002) and Superfamily 1.69 version (<http://supfam.org/SUPERFAMILY/>) (Gough et al., 2001).

\subsection{Comparative modelling and model validation}

A theoretical three-dimensional model for PDI from B. besnoiti (BbPDI) was constructed by comparative modelling by the SwissModel server v. 3.7 (Arnold et al., 2006; Kiefer et al., 2009; Peitsch, 1996) (<http://swissmodel.expasy.org/>) using as template the heterodimer Tapasin-ERp57 crystallographic deduced model (Dong et al., 2009) (PDB code: 3F8U chain C). Superimposition of models and calculation of the root mean square values (RMS) between the model and modelling template using the Carbon alpha fitting, were made by Swiss-Pdb Viewer v. 3.7 (Guex and Peitsch, 1997). RasMol v. 2.6 (Sayle and Milner-White, 1995) and SwissPdb Viewer v. 3.7 were used for visualization of models. Search for structurally similar proteins was done using Dali server v. 2.0 (<http://www.embl-ebi.ac.uk/dali/>) (Holm and Sander, 1993). Model structure validation was performed by Procheck programs (Laskowski et al., 1993; Morris et al., 1992). The substrate pocket was predicted using the WHAT IF program (<http://swift.cmbi.ru. $\mathrm{nl} /$ servers/html/index.html $>$ ) (Vriend, 1990). The model was deposited in the PMDB (<http://mi.caspur.it/PMDB/>) (Castrignanò et al., 2006) under the identification number PM0075875. In this manuscript the BbPDI amino acid sequence numbering is based on ABF48402 entry.

\section{Results and discussion}

\subsection{Molecular characterization of the gene coding for BbPDI}

The gene sequence of $B$. besnoiti PDI was determined and deposited at GenBank under the accession No. DQ490130. The sequence analysis showed an ORF of 1416 nucleotides, comprising three exons, the first one spanning $164 \mathrm{bp}$, the second one $199 \mathrm{bp}$ and a third one $1053 \mathrm{bp}$, which are separated by two introns of $343 \mathrm{bp}$ and $97 \mathrm{bp}$ respectively. The deduced amino acid sequence revealed a protein with 471 residues, presenting the characteristic catalytic thioredoxin motifs $\mathrm{CxxC}$, and showing high amino acid conservation within the catalytic sites regions motif with other PDI entries in databases (Fig. 1). A comparison of the BbPDI amino acid sequence with available PDI sequences from other species of the phylum apicomplexa revealed identity levels as follows: $88.2 \%$ for $N$. caninum (BAD67151) (NcPDI) and $87.7 \%$ for $T$. gondii (CAC28361) (TgPDI); between $48.1 \%$ and $48.2 \%$ for Plasmodium species, P. chabaudi (AAV36000) (PcPDI) P. yoelli (EAA17481) (PyPDI), P. berghei (CAH95379) (PbPDI), P. falciparum (CAC15387) (PfPDI), and P. vivax (ABB72222) (PvPDI); 37.1\% for C. parvum (AAB40710) (CpPDI); between $35.8 \%$ and $34.3 \%$ for Babesia and Theileria species, B. bovis (EDO05830) (BboPDI), B. caballi (BAE54313) (BcPDI), T. annulata (CAI75629) (TaPDI) and T. parva (EAN31157) (TPPDI). 


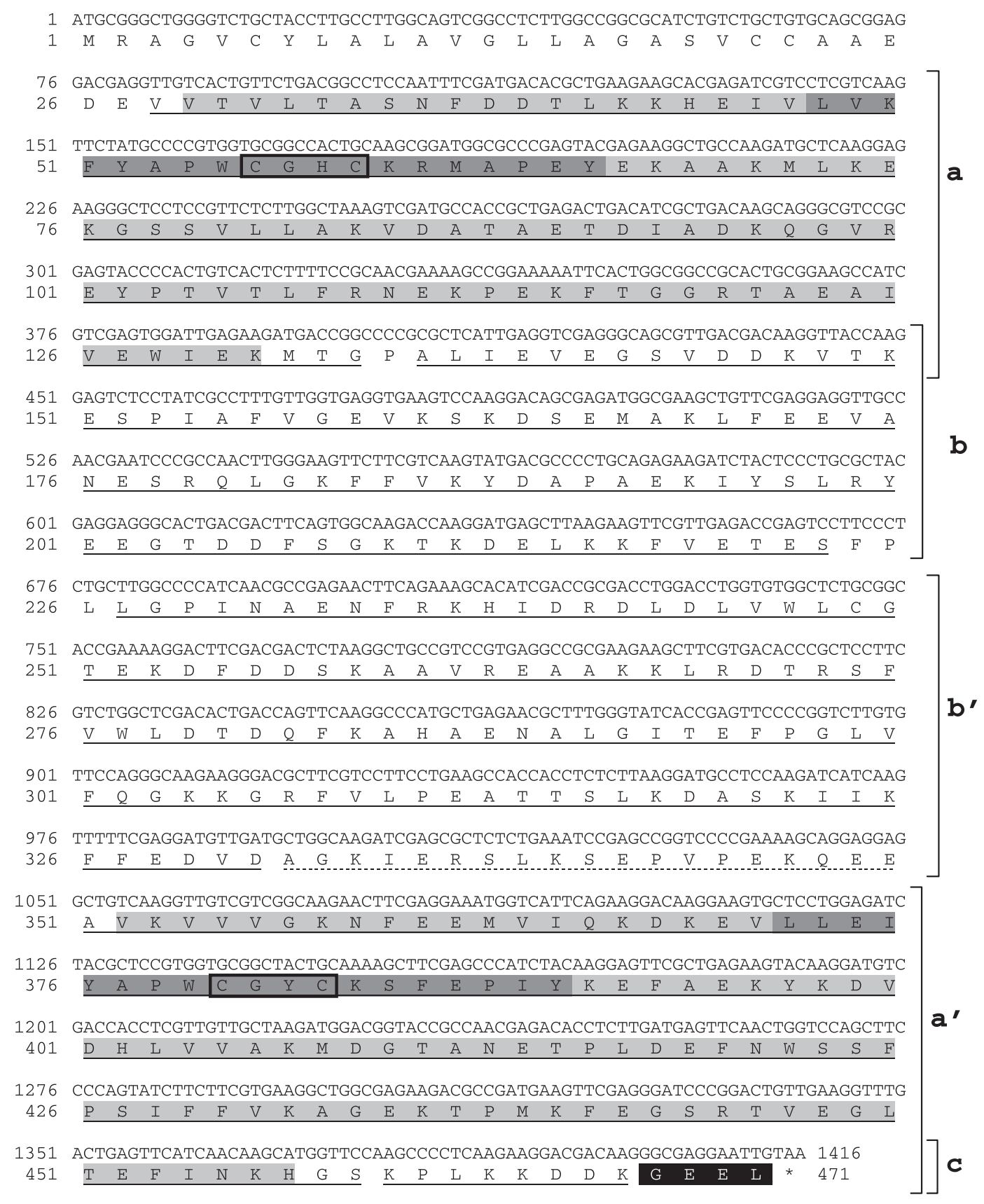

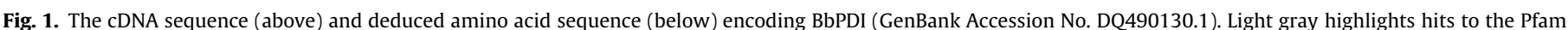

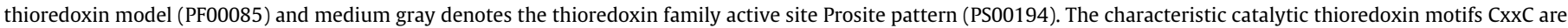

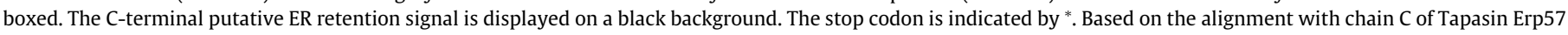
(PDB code 3F8U) the proposed delimitation of $\mathbf{a}, \mathbf{b}, \mathbf{b}$, $\mathbf{a}$ ' and $\mathbf{c}$ domains is showed by brackets and underlined; $x$-linker is dotted-underline.

As expected for members of the thioredoxin superfamily, two thioredoxin domains (PS51352) were identified in BbPDI. These are localized between amino acids 28-134 (a domain) and 351459 (a' domain), and contain the thioredoxin family active site pattern (PS00194) [LIVMF]-[LIVMSTA]-X-[LIVMFYC]-[FYWSTHE]$\mathrm{x}(2)-[$ FYWGTN]-C-[GATPLVE]-[PHYWSTA]-C-x(6)-[LIVMFYWT] between amino acids 48-66 (a domain) and amino acids 372-390 ( $\mathbf{a}^{\prime}$ domain). A putative thioltransferase domain is present between amino acids 223-335. The BbPDI a domain presents the characteristic CGHC eukaryotic active site motif, but there is a substitution of the histidine by a tyrosine in the $\mathbf{a}^{\prime}$ domain active site motif (CGYC), similar to what was described for N. caninum (Naguleswaran et al., 2005) and T. gondii (Meek et al., 2002b). The putative ER retention motif GEEL is present at $\mathrm{C}$ terminus of the amino acid sequence, diverging from the classical KDEL sequence found in eukaryotic ER-resident proteins (PS00014), but again in agreement with $N$. caninum (Naguleswaran et al., 2005) and T. gondii (Meek et al., 2002b).

3.2. B. besnoiti PDI and its relationship to other members of the thioredoxin-like superfamily

BbPDI belongs to the thioredoxin like superfamily (cluster 00388) and is included in the PDI_a family (cluster defined cd02961) and the PDI_a_PDI_a'_c subfamily (cd02995). This subfamily includes ER-resident eukaryotic proteins involved in the 


$\begin{array}{lrl} & & \beta 1 \\ & & \end{array}$

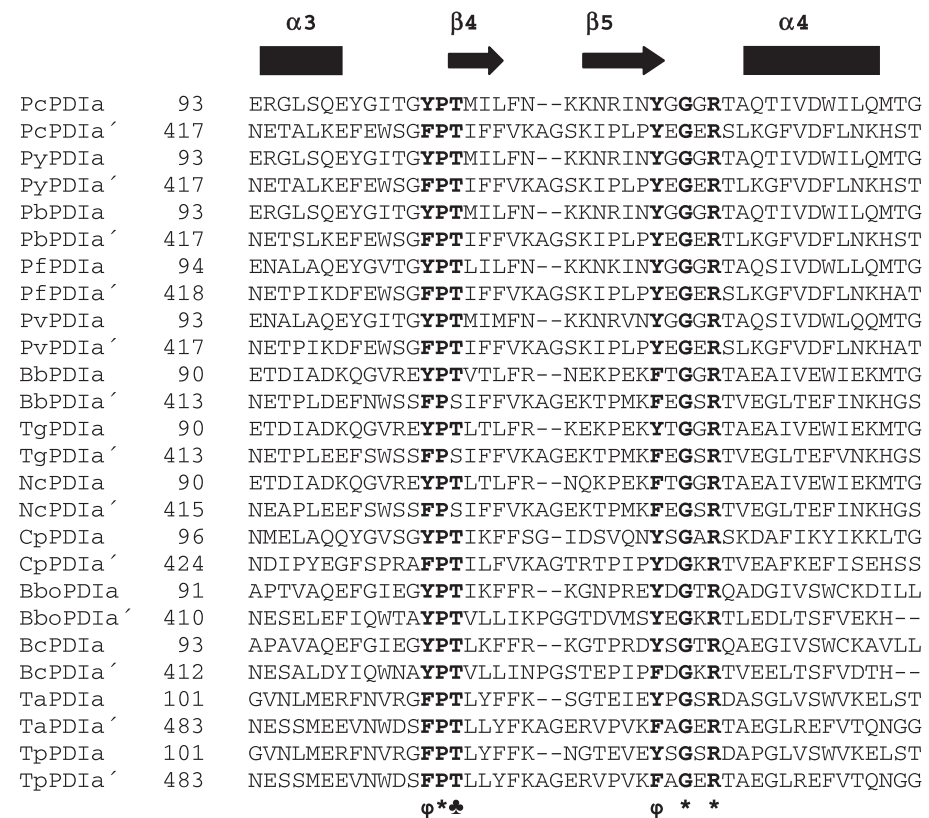

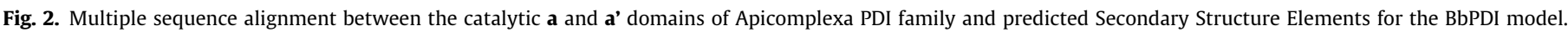

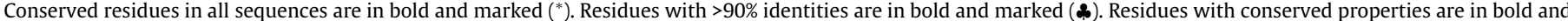

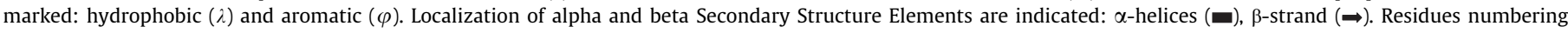

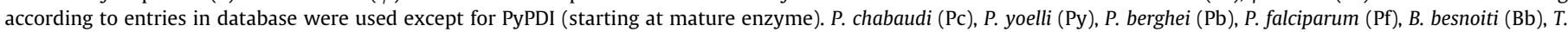
gondii (Tg), N. caninum (Nc), C. parvum (Cp), B. bovis (Bbo), B. caballi (Bc), T. annulata (Ta), T. parva (Tp).

oxidative protein folding (Marchler-Bauer et al., 2009). Structurally, PDI consists of four thioredoxin-like domains, $\mathbf{a}, \mathbf{b}, \mathbf{b}^{\prime}$ and $\mathbf{a}^{\prime}$, plus a highly acidic C-terminal extension c. Two domains contain a redox-active catalytic site (a and $\mathbf{a}^{\prime}$ ), and the other (b and $\mathbf{b}^{\prime}$ ) do not (Kemmink et al., 1995; Kozlov et al., 2010; Marchler-Bauer et al., 2009). Catalytic domains usually contain two cysteines in a CxxC active-site motif (Appenzeller-Herzog and Ellgaard, 2008).

The search for protein neighbors through the web server phylogeny.fr on non redundant databases, identified orthologues in the Muridae family (Rattus norvegicus, Mus musculus), Hominidae family (Homo sapiens, Pan troglodytes), Bovidae family (Bos taurus), Nematoda phylum (Caenorhabitis elegans), in the Phaniasidae fam- ily (Gallus gallus), the Amphibia (Xenopus laevis) and Insecta class ( Culex quinquefasciatus), in the Branchistomidae family (Branchiostoma floridae); Viridiplantae ( Arabidopsis thaliana, Medicago sativa), in the phyla Apicomplexa ( $P$. falciparum), Platyhelminthes (Schistosoma mansoni), Dinoflagellata (Perkinsus marinus) and in the Tetraodontidae family (Tetraodon nigroviridis). No orthologue was detected in bacteria.

The multiple alignment between the $\mathbf{a}$ and $\mathbf{a}^{\prime}$ domains of the PDI amino acid sequences from apicomplexan parasites (Fig. 2) showed that from the 20 residues around the active site motif, VlVkfYAPWCgHCKrmaPeY (B. besnoiti sequence) 12 are identical or their chemical properties are conserved. Also the P103-T104 


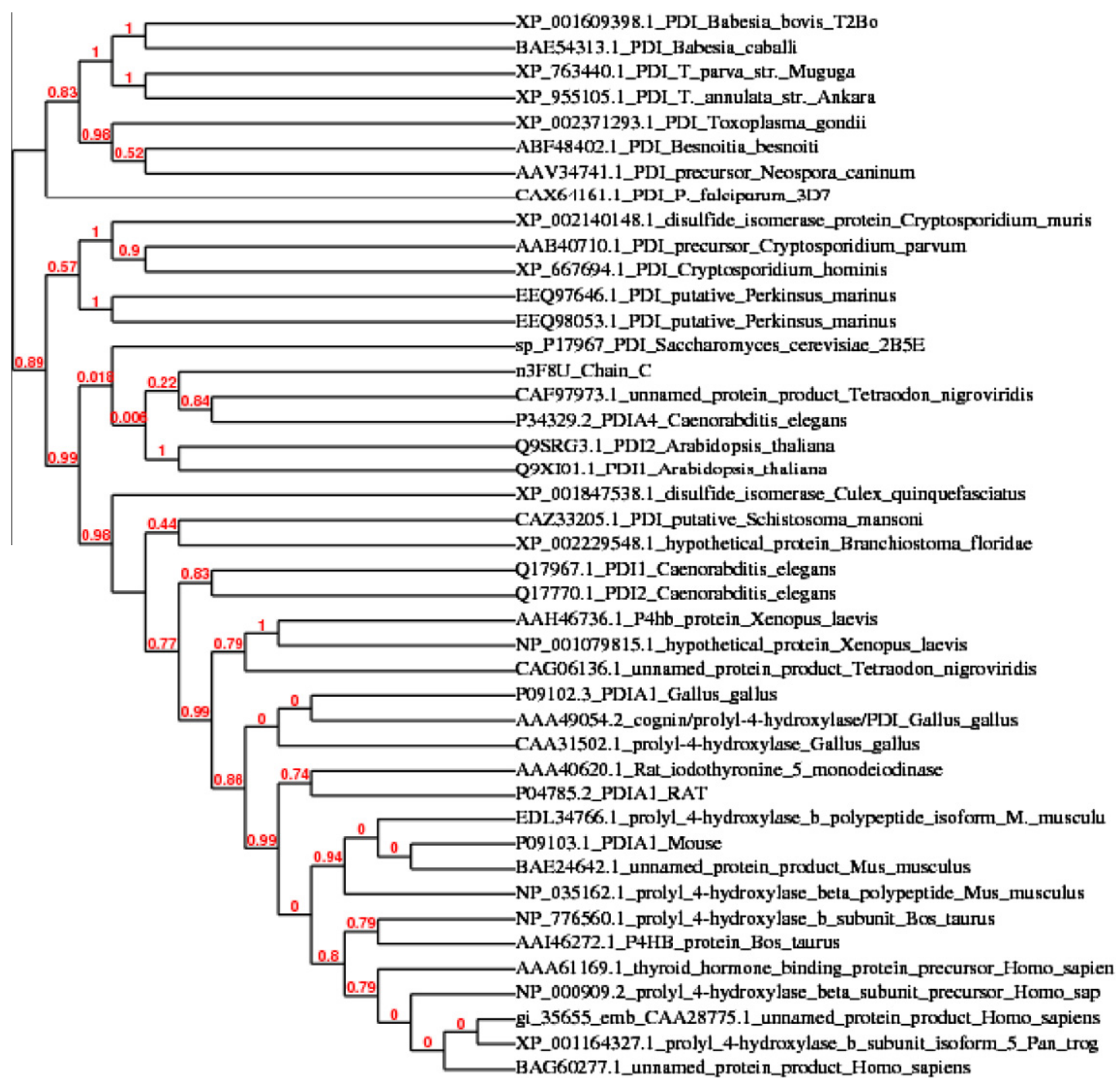

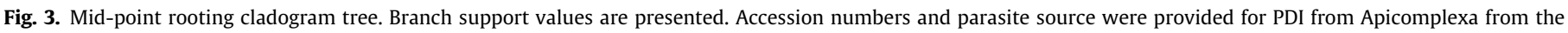

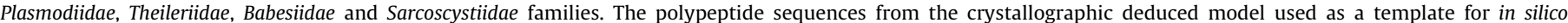

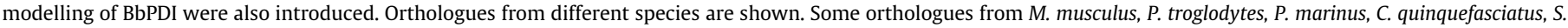
mansoni, B. floridae and X. laevis were omitted due to their similarities to other entries already included.

and R120 residues (a domain) and P426 and R445 (a' domain) ( $B$. besnoiti numbering) are conserved. The aligned residues to T104 in the $\mathbf{a}^{\prime}$ domain are also conserved in all the apicomplexan PDIs except for the Sarcoscytidae in which the Threonine residue was changed to a Serine residue (similar chemical properties), S427 (B. besnoiti, $T$. gondii) and S429 for $N$. caninum. This residue conservation is similar to the one described for the human PDI family (Lappi et al., 2004) and indicates similar functional activities as reported for the equivalent residues in the human PDI family.

Analysis of the phylogenetic tree (Fig. 3) showed that at the first divergent node the Apicomplexa are divided into two branches, the first one comprising the Plasmodium (orthologue) and the Toxoplasma, Neospora, Besnoitia, Babesia and Theileria species homologues and the second one comprising the Cryptosporidiidae members. The first branch diverges again into one containing Toxoplasma, Besnoitia and Neospora PDI homologues and one containing the Babesia and Theileria homologues as expected. Orthologues from $P$. marinus are phylogenically closer to the Cryptosporidiidae than to $B$. besnoiti. Phylogenetically, B. besnoiti PDI is relatively divergent from bovine PDI from $B$. taurus, the target host for $B$. besnoiti infection, with an amino acid sequence identity of only $34 \%$ in 485 amino acids.

\subsection{Analysis of an in silico model of B. besnoiti PDI}

The catalytic sites exhibit a structure that is reminiscent for thioredoxin domains. Both $\mathbf{a}$ and $\mathbf{a}^{\prime}$ domains have a double-wound alternating $\alpha / \beta$ fold, consisting of a 5 -stranded $\beta$-sheet core, enclosed by $4 \alpha$-helices. The active site disulfide is located in a short segment at the $\mathrm{N}$-terminus of helix 2, as described (Kemmink et al., 1996), after a kink caused by the conserved Proline residue P64, (a domain) and P388 (a' domain). The view of the model (Fig. 4A) shows the four thioredoxin domains. Domains a, a', b and $\mathbf{b}^{\prime}$ are, as expected, presenting the five $\beta$-strands characteristic of the fold.

The stereochemical quality of the model, checked by Procheck program, showed that $95.6 \%$ of residues are in the core plus allowed regions of the Ramachandran plot. The model presents $99.3 \%$ of $\mathrm{M} / \mathrm{c}$ bond lengths, $95.1 \%$ of $\mathrm{M} / \mathrm{c}$ bond angles and $88.1 \%$ of planar groups within the expected limits and an overall $\mathrm{G}$ factor of -0.04 . The structural alignment obtained from the superimposition of the model with the 3F8U_C template model showed a RMS of $0.33 \AA$ on $407 \mathrm{C} \alpha$ atoms and a RMS of $1.15 \AA$ on $119 \mathrm{C} \alpha$ atoms from the superimposition with the $S$. cerevisiae PDI crystallographic deduced model 2B5E. Search for structurally similar 
$\mathbf{A}$
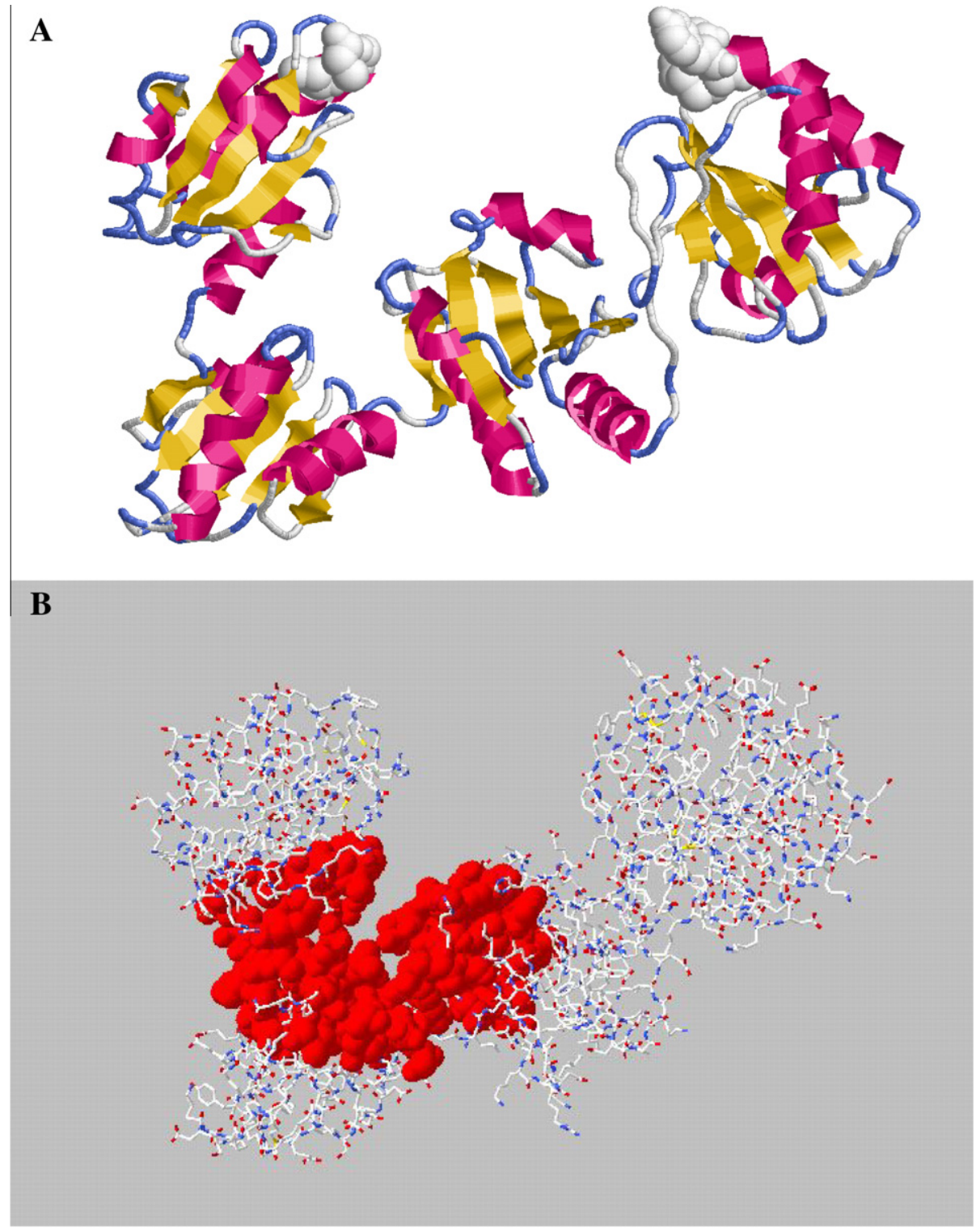

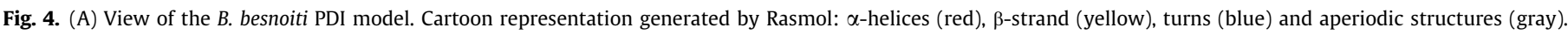

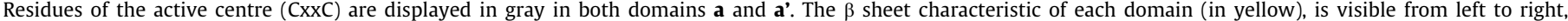

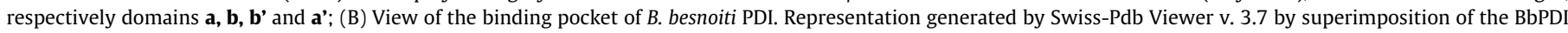

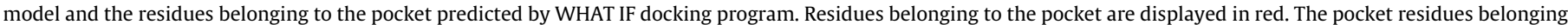
to the domains $\mathbf{a}, \mathbf{b}$ and $\mathbf{b}$ ' are depicted from left to right.

proteins using Dali reveals a very high structural similarity with the used template 3F8U chain $C$ ( $Z$ score 42.6 ) against a $Z$ score 27.1 for $2 \mathrm{~B} 5 \mathrm{E}$ chain $\mathrm{A}$. The phylogenetical distance of the $H$. sapiens Tapasin-ERp57 (PDB code 3F8U_C) and the $S$. cerevisiae PDI (PDB code 2B5E_A) to B. besnoiti PDI is similar for both cases. As the comparative modelling is highly dependent on the degree of amino acid sequence identity, the discrepancies observed on the structural alignment could be due essentially to the low amino acid sequence identity, $28.7 \%$ in 456 amino acid overlap for $2 \mathrm{~B} 5 \mathrm{E}$ protein and $33.6 \%$ in 446 amino acid overlap for 3F8U_C sequence.

\subsection{Analysis of catalytic domains}

In each catalytic site, Cys residues are placed on a and $\mathbf{a}^{\prime}$ domains face to face. On domain a, Cys residues are in a reduced state, in contrast to the oxidized state on $\mathbf{a}^{\prime}$ domain, as occurs in
Humicola insolens (Serve et al., 2010). It was shown (Lappi et al., 2004) that the movement of the side chain of the Arg residues in human PDI, equivalent to $B$. besnoiti R120 and R445 residues, are used by the enzyme to maintain a high $\mathrm{p} K_{\mathrm{a}}$ value for the Cys residue, while allowing the reaction which requires a thiolate to proceed at an appropriate rate. Similar to what was described for human PDI, the side chains of R120 and R445 residues in BbPDI are also distant from the Cys residues of the active site suggesting an identical movement of the Arg side-chains during the catalytic mechanism.

Several studies showed that all domains of PDI act synergistically during catalysis. The experimental results from disulfidebond isomerase (DsbC) from E. coli (Banaszak et al., 2004; McCarthy et al., 2000) and Haemophilus influenza (Zhang et al., 2004) crystal structures, suggest hinge-flexibility within the proteins, which allows movements of the active sites, in order to accommodate the substrate in the cleft between the catalytic 

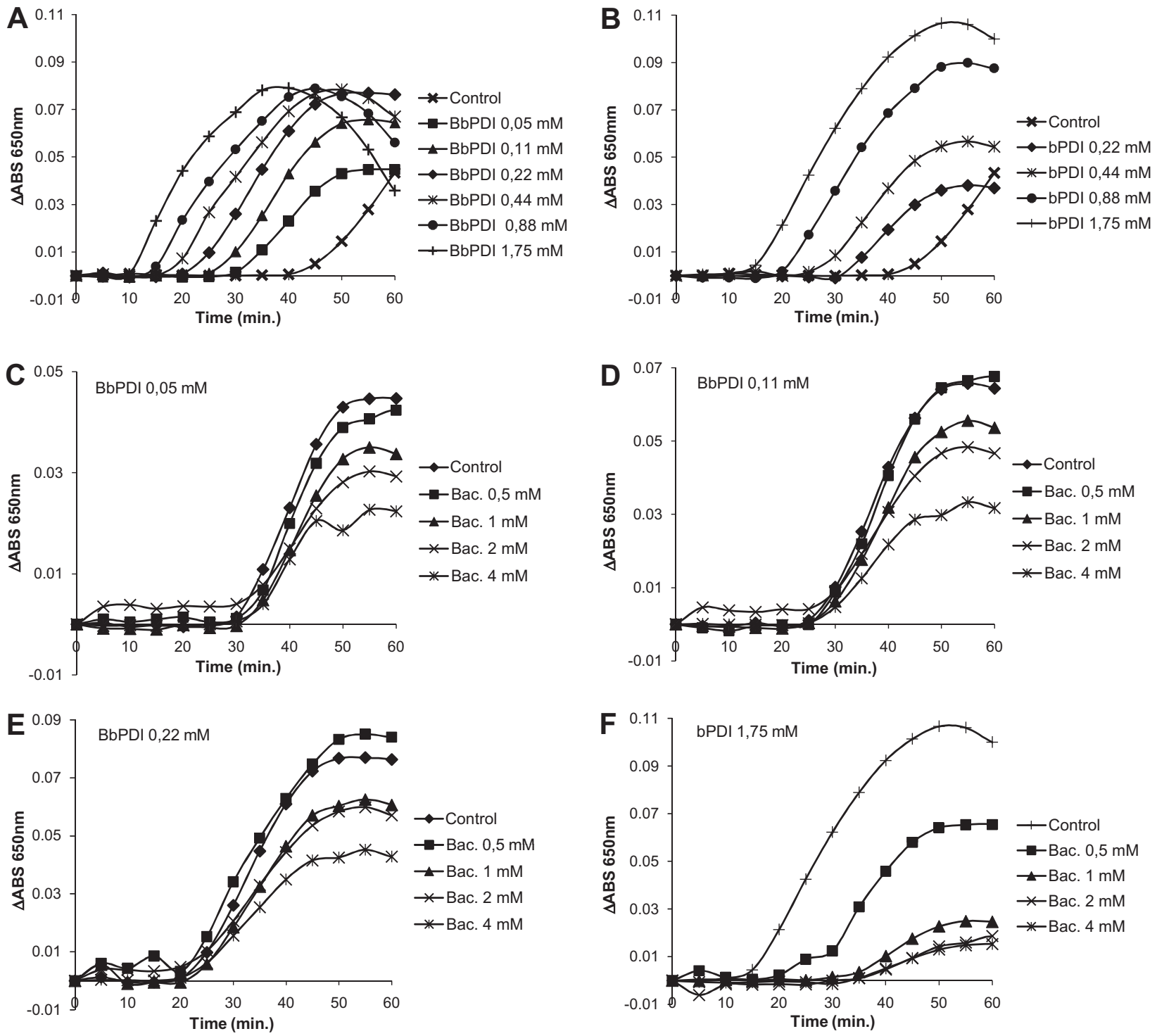

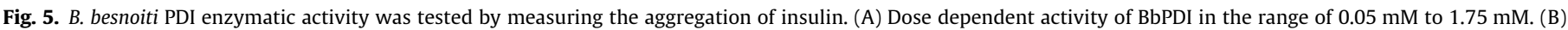

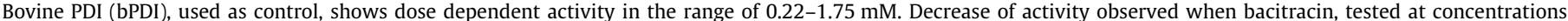
ranging from $0.5 \mathrm{mM}$ to $4 \mathrm{mM}$, was used with a concentration of BbPDI of $0.05 \mathrm{mM}(\mathrm{C}), 0.11 \mathrm{mM}(\mathrm{D})$ and $0.22 \mathrm{mM}(\mathrm{E})$ and bPDI at $1.75 \mathrm{mM}$ (F).

domains, and also differences in the orientation of the catalytic domains (Banaszak et al., 2004; McCarthy et al., 2000). This flexibility, essentially due to the $\boldsymbol{x}$-linker region between $\mathbf{b}^{\prime}$ and $\mathbf{a}^{\prime}$ domains, agrees with the experimental data (Nguyen et al., 2008; Wang et al., 2010) and is fundamental for interaction with folding substrates.

In the BbPDI model the distance of Cys residues of $\mathbf{a}$ and $\mathbf{a}^{\prime}$ catalytic domains is approximately $35 \AA$. In addition to the predicted movement of the R120 and R445 residues, these facts agree with the hypothesis that substrate binding induces domain-movements, leading to a different orientation and distance between $\mathbf{a}$ and $\mathbf{a}^{\prime}$ catalytic domains Cys residues.

Substrate pocket prediction on BbPDI by WHAT IF program (Fig. 4B), detected one pocket comprising residues belonging to a, $\mathbf{b}$ and $\mathbf{b}^{\prime}$ domains. The inclusion in the pocket of residues from $\mathbf{b}$ and $\mathbf{b}^{\prime}$ domains is in agreement with the described participation of several domains in the binding activities of PDI suggesting that b and $\mathbf{b}^{\prime}$ domains act to fix substrates for further catalytic chain action of the $\mathbf{a}$ and $\mathbf{a}^{\prime}$ domains.

\subsection{RecBbPDI catalytic activity and bacitracin inhibition}

The activity of recombinant GST-tagged $B$. besnoiti PDI expressed in $E$. coli, was tested by following the aggregation of insulin at $650 \mathrm{~nm}$, as a consequence of disulfide bond reduction (catalysed by PDI). RecBbPDI is functionally active and shows a dose dependent cross-linking activity in the range of $0.05 \mathrm{mM}$ to $1.75 \mathrm{mM}$ (Fig. 5A). The profile of activity is similar to that observed for bovine PDI (bPDI) (Fig 5B), although at lower enzyme concentrations recBbPDI exhibited higher activity levels and at higher concentrations $(0.88 \mathrm{mM}$ and $1.75 \mathrm{mM})$ recBbPDI activity levels are lower compared to bPDI.

BbPDI activities were sensitive to bacitracin, a classic PDI inhibitor, in a dose-dependent manner at enzyme concentrations ranging from $0.05 \mathrm{mM}$ to $0.22 \mathrm{mM}$ (Fig. 5C, D, E). At higher enzyme concentrations, however, PDI activity was not inhibited in the range of bacitracin concentrations tested $(0.5-4 \mathrm{mM})$ (data not shown). Bovine PDI used as control showed a dose dependent inhibition by bacitracin in the above-mentioned range (Fig. $5 \mathrm{~F}$ ). 


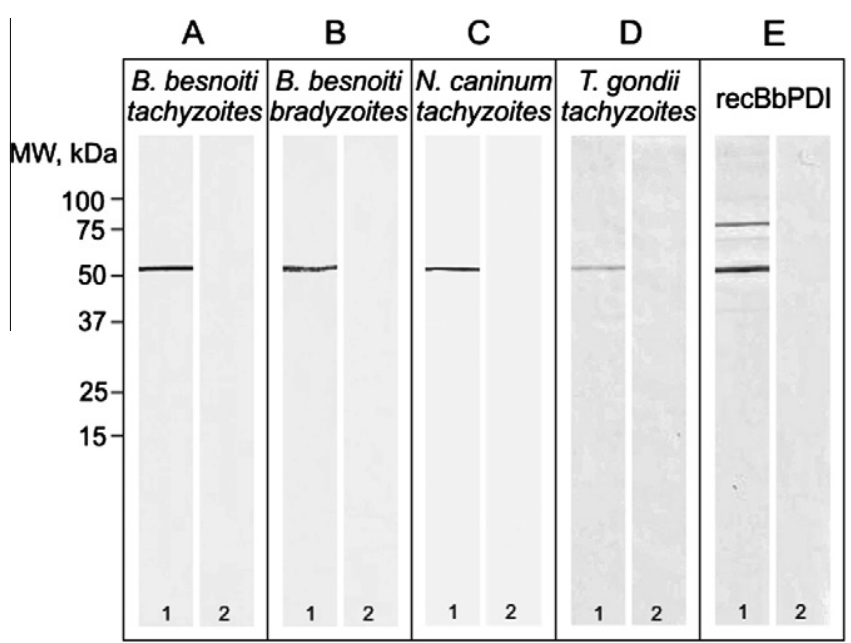

Fig. 6. Western blot analysis using mouse anti-recBbPDI serum (1) and preimmune serum (2) applied (1:1000 dilution) onto: (A) B. besnoiti tachyzoite extract, (B) B. besnoiti bradyzoite extract, (C) N. caninum tachyzoite extract, (D) T. gondii tachyzoite extract and (E) GST-recBbPDI and recBbPDI.

In an attempt to understand differences in sensitivity of recBbPDI and bPDI to bacitracin in silico docking studies were performed. The data suggests that bacitracin makes hydrogen bonds within the substrate pocket residues Glu123 (a domain), Glu151 and Ser 152 (b domain) in the BbPDI model, and with Glu123, Glu153 and Ser154 in a B. taurus PDI model constructed by threading (data not shown). The comparative analysis suggests that bacitracin, due to a different orientation in the substrate pocket, interacts more extensively with the $\mathbf{b}^{\prime}$ domain in bPDI than in BbPDI.

\subsection{Western blotting analysis and immunolocalization of PDI}

In Western blots of $B$. besnoiti tachyzoites and bradyzoites extracts, the anti-recBbPDI serum revealed a band of $53 \mathrm{kDa}$, as expected (Fig. $6 \mathrm{~A}$ and $\mathrm{B}$ ). The antiserum also reacted with a band of similar molecular mass in N. caninum and T. gondii tachyzoite extracts (Fig. 6C and D). This is not surprising, considering the high amino acid sequence homology of PDIs in the three species. Western blots of recBbPDI labeled with anti-recBbPDI antiserum revealed two bands, one corresponding to the GST-PDI-fusion protein ( $\sim 81 \mathrm{kDa})$ and the other corresponding to free PDI devoid of the GST tag ( $\sim 53 \mathrm{kDa})$ (Fig. $6 \mathrm{E})$.

The anti-recBbPDI serum, tested by immunofluorescence on $B$. besnoiti tachyzoites and bradyzoites smears, showed a scattered and uneven intracellular staining, with higher intensity in the perinuclear area, a pattern that is compatible with ER labeling (Fig. 7). $B$. besnoiti PDI staining is similar in both parasite stages, but tachyzoites seems to show a more scattered distribution whereas bradyzoites a more spotted and condensed one with a clear empty intracellular PDI staining area, as shown in the merge image.

\section{Conclusion}

In conclusion, we showed that $B$. besnoiti expresses a PDI with 471 amino acid residues, presenting the two thioredoxin domains and the catalytic motif CxxC as expected for the members of the thioredoxin superfamily. Within the region of the catalytic sites there is a high amino acid sequence identity with PDIs from other apicomplexans, most notably with $N$. caninum and $T$. gondii. Phylogenetic analysis confirms that BbPDI belongs to a cluster comprising the PDIs from these two species. Using the SwissModel server it was possible to construct an in silico model by comparative modelling covering the four domains $\mathbf{a}, \mathbf{b}, \mathbf{b}^{\prime}$ and $\mathbf{a}^{\prime}$. The results obtained by Procheck programs analysis, gave us confidence to use this model as a working hypothesis and the model presents the expected fold for all domains. As described in PDIs from other sources, the distance between catalytic domains and between Cys residues from each domain suggest the presence of the $\boldsymbol{x}$ region linking $\mathbf{b}^{\prime}$ and $\mathbf{a}^{\prime}$ domain, and agree with the hypothesis that substrate binding induces domain movements, leading to different orientations and distances between $\mathbf{a}$ and $\mathbf{a}^{\prime}$ catalytic domains and Cys residues during the catalytic reaction. This confirms what has been found earlier for other PDI models.

Recombinant BbPDI shows a dose dependent catalytic activity and is inhibited by bacitracin. Western blotting results confirm the specificity of produced antiserum against PDI in $B$. besnoiti tachyzoite and bradyzoite extracts, and cross-reactive activity with PDIs from other apicomplexans confirms the close phylogenetic relationship between these species. Immunofluorescence-based localization studies show that this protein is largely associated with the ER in both tachyzoites and bradyzoites. These studies form the basis for future investigations directed towards the exploitation of BbPDI as a potential drug target or vaccine candidate.

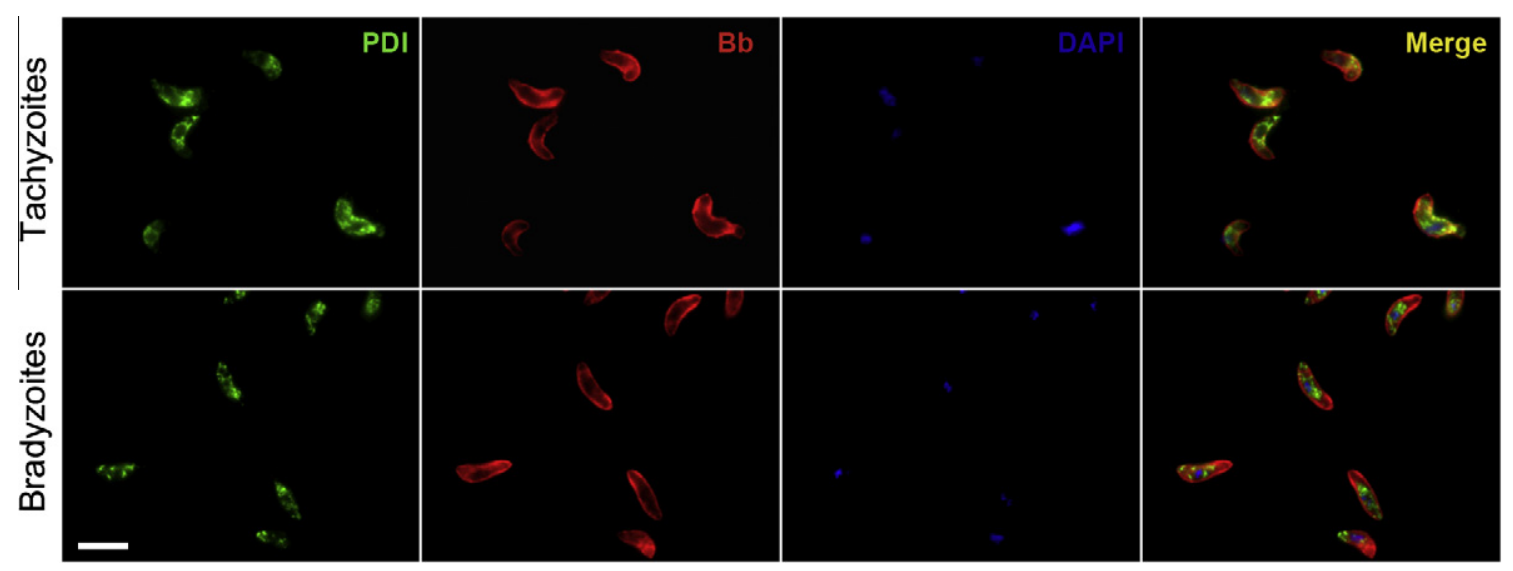

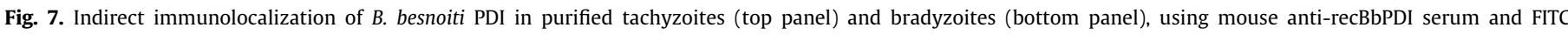

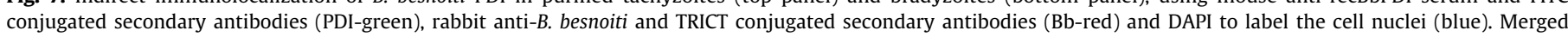

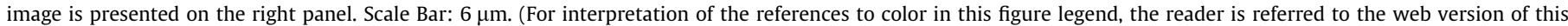
article.) 


\section{Acknowledgments}

This work was supported by the Foundation for Science and Technology (Portugal) Project PTDC/CVT/65674/2006. Eduardo Marcelino was supported by the PhD grant SFRH/BD/31445/2006 and Tiago Martins by the PhD grant SFRH/BD/19059/2004. Joana Morais was supported by a grant of the PEPAP program (Portugal) and by a research grant included on the above FCT project. Andrew Hemphill was supported by the Swiss National Science Foundation (grant no. 31003A_127374).

\section{References}

Agosti, M., Belloli, A., Morini, M., Vacirca, G., 1994. Segnalazione di un focolaio di Besnoitiosi in bovini da carne importati. Praxis 15, 5-6.

Altschul, S.F., Gish, W., Miller, W., Myers, E.W., Lipman, D.J., 1990. Basic local alignment search tool. Journal of Molecular Biology 215, 403-410.

Alzieu, J.P., Dorchies, P., Schelcher, F., Gottstein, B., 2007. L'extension de la besnoitiose bovine en France. Le Point Vétérinaire 38, 37-43.

Appenzeller-Herzog, C., Ellgaard, L., 2008. The human PDI family: versatility packed into a single fold. Biochimica et Biophysica Acta 1783, 535-548.

Arnold, K., Bordoli, L., Kopp, J., Schwede, T., 2006. The SWISS-MODEL workspace. a web-based environment for protein structure homology modelling. Bioinformatics 22, 195-201.

Banaszak, K., Mechin, I., Frost, G., Rypniewski, W., 2004. Structure of the reduced disulfide-bond isomerase DsbC from Escherichia coli. Acta Crystallographica. Section D, Biological Crystallography 60, 1747-1752.

Basson, P.A., McCully, R.M., Bigalke, R.D., 1970. Observations on the pathogenesis of bovine and antelope strains of Besnoitia besnoiti (Marotel, 1912) infection in cattle and rabbits. Onderstepoort Journal of Veterinary Research 37, 105-126.

Ben, A.Y., Chenik, M., Louzir, H., Dellagi, K., 2002. Identification of a disulfide isomerase protein of Leishmania major as a putative virulence factor. Infection and Immunity 70, 3576-3585.

Bigalke, R.D., Prozesky, L., 2004. Besnoitiosis. In: Coetzer, J.A.W., Tustin, R.C. (Eds.) Infectious Diseases of Livestock. Oxford University Press, Cape Town, pp. 351359.

Blunt, D.S., Montelone, B.A., Upton, S.J., Khramtsov, N.V., 1996. Sequence of the parasitic protozoan, Cryptosporidium parvum, putative protein disulfide isomerase-encoding DNA. Gene 181, 221-223.

Bourdeau, P.J., Cesbron, N., Alexandre, F., Marchand, A.M., Desvaux, J.P., Douart, A., 2004. Outbreak of bovine besnoitiosis, Besnoitia besnoiti in the west of France and its diagnosis by immunofluorescence assay. In: IX European Multicolloquium of Parasitology, pp. 459-460..

Byrne, L.J., Sidhu, A., Wallis, A.K., Ruddock, L.W., Freedman, R.B., Howard, M.J., Williamson, R.A., 2009. Mapping of the ligand-binding site on the b' domain of human PDI: interaction with peptide ligands and the $\mathrm{x}$-linker region. Biochemical Journal 423, 209-217.

Castillo, J.A., Marcén, J.M., Ortega-Mora, L.M., Alvarez-Garcia, G., 2009. La besnoitiosis bovina, presentada como una enfermedad emergente europea. Albeitar 127, 24-25.

Castrignanò, T., De Meo, P.D., Cozzetto, D., Talamo, I.G., Tramontano, A., 2006. The PMDB protein model database. Nucleic Acids Research 34, D306-D309.

Cortes, H., Leitao, A., Vidal, R., Vila-Vicosa, M.J., Ferreira, M.L., Caeiro, V., Hjerpe, C.A 2005. Besnoitiosis in bulls in Portugal. Veterinary Record 157, 262-264.

Cortes, H.C., Mueller, N., Esposito, M., Leitao, A., Naguleswaran, A., Hemphill, A., 2007. In vitro efficacy of nitro- and bromo-thiazolyl-salicylamide compounds (thiazolides) against Besnoitia besnoiti infection in Vero cells. Parasitology 134 975-985.

Cortes, H.C., Nunes, S., Reis, Y., Staubli, D., Vidal, R., Sager, H., Leitao, A., Gottstein, B. 2006a. Immunodiagnosis of Besnoitia besnoiti infection by ELISA and Western blot. Veterinary Parasitology 141, 216-225.

Cortes, H.C., Reis, Y., Waap, H., Vidal, R., Soares, H., Marques, I., Pereira, D.F. Fazendeiro, I., Ferreira, M.L., Caeiro, V., Shkap, V., Hemphill, A., Leitao, A., 2006b. Isolation of Besnoitia besnoiti from infected cattle in Portugal. Veterinary Parasitology 141, 226-233.

Debache, K., Guionaud, C., Alaeddine, F., Hemphill, A., 2010. Intraperitoneal and intra-nasal vaccination of mice with three distinct recombinant Neospora caninum antigens results in differential effects with regard to protection against experimental challenge with Neospora caninum tachyzoites. Parasitology 137, 229-240.

Dereeper, A., Guignon, V., Blanc, G., Audic, S., Buffet, S., Chevenet, F., Dufayard, J.F. Guindon, S., Lefort, V., Lescot, M., Claverie, J.M., Gascuel, O., 2008. Phylogeny.fr: robust phylogenetic analysis for the non-specialist. Nucleic Acids Research 36, W465-W469.

Dong, G., Wearsch, P.A., Peaper, D.R., Cresswell, P., Reinisch, K.M., 2009. Insights into MHC class I peptide loading from the structure of the tapasin-ERp57 thiol oxidoreductase heterodimer. Immunity. 30, 21-32.

Ebel, T., Bender, K., Bocskor, U., Binder, B.R., Lipp, J., 2002. Mp23, a Theileria parva transmembrane protein with homology to the protein disulfide isomerase family. Molecular and Biochemical Parasitology 121, 265-268.
Edman, J.C., Ellis, L., Blacher, R.W., Roth, R.A., Rutter, W.J., 1985. Sequence of protein disulphide isomerase and implications of its relationship to thioredoxin. Nature $317,267-270$

Ellis, J.T., Holmdahl, O.J., Ryce, C., Njenga, J.M., Harper, P.A., Morrison, D.A., 2000. Molecular phylogeny of Besnoitia and the genetic relationships among Besnoitia of cattle, wildebeest and goats. Protist 151, 329-336.

Fernandez-Garcia, A., Alvarez-Garcia, G., Risco-Castillo, V., Aguado-Martinez, A., Marcen, J.M., Rojo-Montejo, S., Castillo, J.A., Ortega-Mora, L.M., 2010. Development and use of an indirect ELISA in an outbreak of bovine besnoitiosis in Spain. Veterinary Record 166, 818-822.

Ferrari, D.M., Soling, H.D., 1999. The protein disulphide-isomerase family: unravelling a string of folds. Biochemical Journal 339, 1-10.

Florent, I., Mouray, E., Dali, A.F., Drobecq, H., Girault, S., Schrevel, J., Sergheraert, C., Grellier, P., 2000. Cloning of Plasmodium falciparum protein disulfide isomerase homologue by affinity purification using the antiplasmodial inhibitor 1, 4-bis[3[N-(cyclohexyl methyl)amino]propyl]piperazine. FEBS Letters 484, 246-252.

Gattiker, A., Gasteiger, E., Bairoch, A., 2002. ScanProsite: a reference implementation of a PROSITE scanning tool. Applied Bioinformatics 1, 107-108.

Gollnick, N.S., Gentile, A., Schares, G., 2010. Diagnosis of bovine besnoitiosis in a bull born in Italy. Veterinary Record 166, 599.

Gough, J., Karplus, K., Hughey, R., Chothia, C., 2001. Assignment of homology to genome sequences using a library of hidden Markov models that represent all proteins of known structure. Journal of Molecular Biology 313, 903-919.

Guex, N., Peitsch, M.C., 1997. SWISS-MODEL and the Swiss-PdbViewer: an environment for comparative protein modeling. Electrophoresis 18, 27142723.

Hatahet, F., Ruddock, L.W., Ahn, K., Benham, A., Craik, D., Ellgaard, L., Ferrari, D., Ventura, S., 2009. Protein disulfide isomerase: a critical evaluation of its function in disulfide bond formation. Antioxidants and Redox Signaling 11, 2807-2850.

Holm, L., Sander, C., 1993. Protein structure comparison by alignment of distance matrices. Journal of Molecular Biology 233, 123-138.

Hong, B.X., Soong, L., 2008. Identification and enzymatic activities of four protein disulfide isomerase (PDI) isoforms of Leishmania amazonensis. Parasitology Research 102, 437-446.

Huang, X., Miller, W., 1991. A Time-Efficient, Linear-Space Local Similarity Algorithm. Advances in Applied Mathematics 12, 337-357.

Irigoien, M., Del, C.E., Gallego, M., Lopez-Bernad, F., Quilez, J., Sanchez-Acedo, C., 2000. Immunohistochemical study of the cyst of Besnoitia besnoiti. Veterinary Parasitology 91, 1-6.

Kemmink, J., Darby, N.J., Dijkstra, K., Scheek, R.M., Creighton, T.E., 1995. Nuclear magnetic resonance characterization of the N-terminal thioredoxin-like domain of protein disulfide isomerase. Protein Science 4, 2587-2593.

Kemmink, J., Darby, N.J., Dijkstra, K., Nilges, M., Creighton, T.E., 1996. Structure determination of the N-terminal thioredoxin-like domain of protein disulfide isomerase using multidimensional heteronuclear 13C/15N NMR spectroscopy. Biochemistry 35, 7684-7691.

Kemmink, J., Dijkstra, K., Mariani, M., Scheek, R.M., Penka, E., Nilges, M., Darby, N.J., 1999. The structure in solution of the $\mathrm{b}$ domain of protein disulfide isomerase. Journal of Biomolecular NMR 13, 357-368.

Kiefer, F., Arnold, K., Kunzli, M., Bordoli, L., Schwede, T., 2009. The SWISS-MODEL Repository and associated resources. Nucleic Acids Research 37, D387-D392.

Kozlov, G., Maattanen, P., Thomas, D.Y., Gehring, K., 2010. A structural overview of the PDI family of proteins. FEBS Journal 277, 3924-3936.

Kumar, S., Nei, M., Dudley, J., Tamura, K., 2008. MEGA: a biologist-centric software for evolutionary analysis of DNA and protein sequences. Briefings in Bioinformatics 9, 299-306.

Lambert, N., Freedman, R.B., 1985. The latency of rat liver microsomal protein disulphide-isomerase. Biochemical Journal 228, 635-645.

Lappi, A.K., Lensink, M.F., Alanen, H.I., Salo, K.E., Lobell, M., Juffer, A.H., Ruddock, L.W., 2004. A conserved arginine plays a role in the catalytic cycle of the protein disulphide isomerases. Journal of Molecular Biology 335, 283-295.

Laskowski, R.A., MacArthur, M.W., Moss, D.S., Thornton, J.M., 1993. PROCHECK: a program to check the stereochemical quality of protein structures. Journal of Applied Crystallography 26, 283-291.

Liao, M., Ma, L., Bannai, H., Lee, E.G., Xie, Z., Tang, X., Zhang, H., Xuan, X., Fujisaki, K., 2006. Identification of a protein disulfide isomerase of Neospora caninum in excretory-secretory products and its IgA binding and enzymatic activities. Veterinary Parasitology 139, 47-56.

Lienard, E., Salem, A., Grisez, C., Prevot, F., Bergeaud, J.P., Franc, M., Gottstein, B. Alzieu, J.P., Lagalisse, Y., Jacquiet, P., 2010. A longitudinal study of Besnoitia besnoiti infections and seasonal abundance of Stomoxys calcitrans in a dairy cattle farm of southwest France. Veterinary Parasitology 177, 20-27.

Lundstrom, J., Holmgren, A., 1990. Protein disulfide-isomerase is a substrate for thioredoxin reductase and has thioredoxin-like activity. Journal of Biological Chemistry 265, 9114-9120.

Ma, G.Y., Zhang, J.Z., Yin, G.R., Zhang, J.H., Meng, X.L., Zhao, F., 2009. Toxoplasma gondii: proteomic analysis of antigenicity of soluble tachyzoite antigen. Experimental Parasitology 122, 41-46.

Mahajan, B., Noiva, R., Yadava, A., Zheng, H., Majam, V., Mohan, K.V., Moch, J.K., Haynes, J.D., Nakhasi, H., Kumar, S., 2006. Protein disulfide isomerase assisted protein folding in malaria parasites. International Journal for Parasitology 36, 1037-1048.

Mandel, R., Ryser, H.J., Ghani, F., Wu, M., Peak, D., 1993. Inhibition of a reductive function of the plasma membrane by bacitracin and antibodies against protein disulfide-isomerase. Proceedings of the National Academy of Sciences of the USA 90, 4112-4116. 
Marchler-Bauer, A., Anderson, J.B., Chitsaz, F., Derbyshire, M.K., DeWeese-Scott, C., Fong, J.H., Geer, L.Y., Geer, R.C., Gonzales, N.R., Gwadz, M., He, S., Hurwitz, D.I. Jackson, J.D., Ke, Z., Lanczycki, C.J., Liebert, C.A., Liu, C., Lu, F., Lu, S., Marchler, G.H., Mullokandov, M., Song, J.S., Tasneem, A., Thanki, N., Yamashita, R.A., Zhang, D., Zhang, N., Bryant, S.H., 2009. CDD: specific functional annotation with the Conserved Domain Database. Nucleic Acids Research 37, D205-D210.

McCarthy, A.A., Haebel, P.W., Torronen, A., Rybin, V., Baker, E.N., Metcalf, P., 2000. Crystal structure of the protein disulfide bond isomerase, DsbC from Escherichia coli. Nature Structural and Molecular Biology 7, 196-199.

Meek, B., Back, J.W., Klaren, V.N., Speijer, D., Peek, R., 2002a. Conserved regions of protein disulfide isomerase are targeted by natural IgA antibodies in humans. International Immunology 14, 1291-1301.

Meek, B., Back, J.W., Klaren, V.N., Speijer, D., Peek, R., 2002b. Protein disulfide isomerase of Toxoplasma gondii is targeted by mucosal IgA antibodies in humans. FEBS Letters 522, 104-108.

Mehlhorn, H., Klimpel, S., Schein, E., Heydorn, A.O., Al-Quraishy, S., Selmair, J., 2009. Another African disease in Central Europa: Besnoitiosis of cattle I. Light and electron microscopical study. Parasitology Research 104, 861-868.

Morris, A.L., MacArthur, M.W., Hutchinson, E.G., Thornton, J.M., 1992. Stereochemical quality of protein structure coordinates. Proteins 12, 345-364.

Mouray, E., Moutiez, M., Girault, S., Sergheraert, C., Florent, I., Grellier, P., 2007. Biochemical properties and cellular localization of Plasmodium falciparum protein disulfide isomerase. Biochimie 89, 337-346.

Naguleswaran, A., Alaeddine, F., Guionaud, C., Vonlaufen, N., Sonda, S., Jenoe, P., Mevissen, M., Hemphill, A., 2005. Neospora caninum protein disulfide isomerase is involved in tachyzoite-host cell interaction. International Journal for Parasitology 35, 1459-1472.

Nguyen, V.D., Wallis, K., Howard, M.J., Haapalainen, A.M., Salo, K.E., Saaranen, M.J., Sidhu, A., Wierenga, R.K., Freedman, R.B., Ruddock, L.W., Williamson, R.A., 2008. Alternative conformations of the $\mathrm{x}$ region of human protein disulphideisomerase modulate exposure of the substrate binding b' domain. Journal of Molecular Biology 383, 1144-1155.

Novo, C., Martins, T.M., Prata, S., Lopes, A., Armada, A., 2009. Gene sequencing, modelling and immunolocalization of the protein disulfide isomerase from Plasmodium chabaudi. International Journal of Biological Macromolecules 45, 399-406.

Padilla, A., Noiva, R., Lee, N., Mohan, K.V., Nakhasi, H.L., Debrabant, A., 2003. An atypical protein disulfide isomerase from the protozoan parasite Leishmania containing a single thioredoxin-like domain. Journal of Biological Chemistry 278, 1872-1878.

Peitsch, M.C., 1996. ProMod and Swiss-Model: Internet-based tools for automated comparative protein modelling. Biochemical Society Transactions 24, 274-279.

Reis, Y., Cortes, H., Viseu, M.L., Fazendeiro, I., Leitao, A., Soares, H., 2006. Microtubule cytoskeleton behavior in the initial steps of host cell invasion by Besnoitia besnoiti. FEBS Letters 580, 4673-4682.

Sanger, F., Nicklen, S., Coulson, A.R., 1977. DNA sequencing with chain-terminating inhibitors. Proceedings of the National Academy of Sciences of the United States of America 74, 5463-5467.
Sayle, R.A., Milner-White, E.J., 1995. RASMOL: biomolecular graphics for all. Trends in Biochemical Sciences 20, 374.

Schares, G., Basso, W., Majzoub, M., Cortes, H.C., Rostaher, A., Selmair, J., Hermanns, W., Conraths, F.J., Gollnick, N.S., 2009. First in vitro isolation of Besnoitia besnoit from chronically infected cattle in Germany. Veterinary Parasitology 163, 315322.

Schwaller, M., Wilkinson, B., Gilbert, H.F., 2003. Reduction-reoxidation cycles contribute to catalysis of disulfide isomerization by protein-disulfide isomerase. Journal of Biological Chemistry 278, 7154-7159.

Serve, O., Kamiya, Y., Maeno, A., Nakano, M., Murakami, C., Sasakawa, H., Yamaguchi, Y., Harada, T., Kurimoto, E., Yagi-Utsumi, M., Iguchi, T., Inaba, K. Kikuchi, J., Asami, O., Kajino, T., Oka, T., Nakasako, M., Kato, K., 2010. Redoxdependent domain rearrangement of protein disulfide isomerase coupled with exposure of its substrate-binding hydrophobic surface. Journal of Molecular Biology 396, 361-374.

Shin, Y.S., Lee, E.G., Shin, G.W., Kim, Y.R., Lee, E.Y., Kim, J.H., Jang, H., Gershwin, L.J. Kim, D.Y., Kim, Y.H., Kim, G.S., Suh, M.D., Jung, T.S., 2004. Identification of antigenic proteins from Neospora caninum recognized by bovine immunoglobulins M, E, A and G using immunoproteomics. Proteomics 4, 3600-3609.

Shin, Y.S., Shin, G.W., Kim, Y.R., Lee, E.Y., Yang, H.H., Palaksha, K.J., Youn, H.J., Kim J.H., Kim, D.Y., Marsh, A.E., Lakritz, J., Jung, T.S., 2005. Comparison of proteome and antigenic proteome between two Neospora caninum isolates. Veterinary Parasitology 134, 41-52.

Shkap, V., Pipano, E., Ungar-Waron, H., 1987. Besnoitia besnoiti: chemotherapeutic trials in vivo and in vitro. Revue d Elevage et de Medecine Veterinaire des Pays Tropicaux 40, 259-264.

Smith, A.M., Chan, J., Oksenberg, D., Urfer, R., Wexler, D.S., Ow, A., Gao, L., McAlorum, A., Huang, S.G., 2004. A high-throughput turbidometric assay for screening inhibitors of protein disulfide isomerase activity. Journal of Biomolecular Screening 9, 614-620.

Turano, C., Coppari, S., Altieri, F., Ferraro, A., 2002. Proteins of the PDI family: unpredicted non-ER locations and functions. Journal of Cellular Physiology 193, $154-163$.

Vriend, G., 1990. WHAT IF: a molecular modeling and drug design program. Journal of Molecular Graphics and Modelling 8 (52-6), 29.

Wang, C., Chen, S., Wang, X., Wang, L., Wallis, A.K., Freedman, R.B., Wang, C.C., 2010 Plasticity of human protein disulfide isomerase: evidence for mobility around the X-linker region and its functional significance. Journal of Biological Chemistry 285, 26788-26797.

Wilkinson, B., Gilbert, H.F., 2004. Protein disulfide isomerase. Biochimica et Biophysica Acta 1699, 35-44.

Zhang, M., Monzingo, A.F., Segatori, L., Georgiou, G., Robertus, J.D., 2004. Structure of DsbC from Haemophilus influenzae. Acta Crystallographica. Section D, Biological Crystallography 60, 1512-1518. 